\title{
Representações sociais e práticas em escolas do ensino fundamental: efeitos de unidades de polícia pacificadora (UPP) no Rio de Janeiro
}

\author{
Social representations and practices in elementary schools: effects of police \\ pacification unit (UPP) in Rio de Janeiro
}

\author{
Rita de Cássia Pereira Lima ${ }^{1}$ \\ Ivan Soares dos Santos ${ }^{2}$
}

\begin{abstract}
RESUMO: O objetivo do estudo é refletir sobre relações entre representações sociais e práticas com base em um estudo sobre representações de Unidades de Polícia Pacificadora (UPP) elaboradas por professores do Ensino Fundamental no Rio de Janeiro. Foram realizadas entrevistas semidirigidas com 30 docentes de três escolas, 10 em cada escola, respectivamente Escola 1, Escola 2 e Escola 3. A análise apoiou-se na análise de conteúdo temática. Para os professores da Escola 1, uma unidade da UPP em frente ao portão principal provocou melhora nas práticas desenvolvidas na escola. A representação social desse objeto social, presente em interações e práticas cotidianas, objetivou-se no termo "segurança". Na Escola 2, com favelas próximas e sem UPP, os docentes não formaram representação social desse objeto, ausente de suas práticas. Com desconfiança da UPP, o "Estado" é o maior criticado, destaque no discurso desse grupo. Quanto aos professores da Escola 3, situada em bairro tradicional do Rio, sem favelas e sem UPP, esse objeto também não está nas práticas cotidianas, não havendo representação social. Um tipo de "segurança ideal", mais no plano da expectativa que da concretização, coordena o discurso desse grupo. As diferenças nos resultados entre os três grupos mostram que a presença da UPP nas práticas escolares, assim como das práticas na elaboração de representações sociais sobre esse objeto, está associada ao contexto de interação entre a UPP e os sujeitos. Se os campos de prática e de interações são diferentes, o campo representacional tende a ser diferente também.
\end{abstract}

Palavras-chave: representações sociais; práticas; unidade de polícia pacificadora (UPP); professores; escola.

\begin{abstract}
The aim of this paper is to reflect upon the relation between social representations and practices based on a study on representations of Police Pacification Units ( UPP, in Brazilian Portuguese) done by Middle School teachers in Rio de Janeiro. Thirty teachers from three schools (10 from each school respectively School 1, School 2, School 3) had taken part in a semi-guided interview. The analysis has been backed up by thematic content analysis. According to the teachers in School 1, a UPP unit across from the main gate of the school has improved the practices at school. The social representation of this social medium, present in daily practices and interactions, turned out as "security". In School 2, which is surrounded by slums and without UPPS, the teachers did not constitute any social representation of this medium, missing its practices. With scepticism over UPPS, the Government is the one to be criticized, pointed out in those groups speech. Regarding School 3, placed in a traditional neighborhood in Rio, without slums or UPPS, that medium is not among in daily practices either, therefore, there is not social representation. Some kind of "ideal safety", more in terms of expectations than in terms of accomplishment, which coordinates this group's speech. The differences in the results among the three groups show that the presence of UPPS in school practices as well as the practices in the construction of social representation over that medium are associated to the context of the
\end{abstract}

\footnotetext{
${ }^{1}$ Doutora em Sciences de I'Éducation pela Université René Descartes - Paris V. Docente do Programa de Pós-Graduação em Educação da Universidade Estácio de Sá - Rio de Janeiro, RJ, Brasil. E-mail: ritaplima2008@gmail.com.

2 Doutor em Educação pelo Programa de Pós-Graduação em Educação da Universidade Estácio de Sá. Coordenador Pedagógico na Fundação Osório - Rio de Janeiro, RJ, Brasil.
} 
interaction between the UPPS and the individual. If the practice field and the interaction field are different, the representation field tends to be different as well.

Keywords: social representation; practices; Police Pacification Unit (UPP); teachers; school.

\section{Introdução}

No campo da Teoria das Representações Sociais (TRS), a discussão sobre as relações entre representações sociais e práticas não é recente, ainda que seja atual. De acordo com Guimelli (2003), na década de 1980, Flament (1987) já chamava a atenção para a necessidade de se analisar as relações entre práticas e representações quando se busca compreender a dinâmica das representações sociais. Abric (1994) e Flament (2001) fazem referência a Jodelet e Moscovici $(1990,287)$, quando os autores afirmam que a área das práticas sociais não é suficientemente estudada na Psicologia Social e propõem que "as práticas são sistemas de ação socialmente estruturados e instituídos em relação com papéis". Sobre essa definição Flament (2001) expõe as seguintes questões: a qual teoria da ação e a qual teoria de papéis ela remete?

Essa reflexão inicial mostra a necessidade de desenvolver e aprofundar estudos sobre relações teóricas e metodológicas entre representações sociais e práticas, tema destacado por autores como Rouquette (2000), Campos (2003), Wolter e Sá (2013), além dos já citados acima. Um aspecto central, na Psicologia e na abordagem psicossocial da TRS, é a relação entre pensamento e ação. De acordo com Rouquette (2000, p. 39), diversas pesquisas mostram que o que se pensa depende do que se faz, ou o que se vem pensar depende do que se fez ou se foi levado a fazer, e "aquilo que fazemos em dado momento, depende daquilo que pensamos então, ou daquilo que pensamos anteriormente".

Como afirma Abric (1994), a obra de Jodelet (1989/2015) se constitui em estudo completo das relações entre representações e práticas sociais, mostrando que não é possível dissociar a representação, o discurso e a prática. A autora expõe que algumas práticas trazem à tona aspectos da representação que não são verbalizados e evidencia que todo estudo de representação social deve considerar os discursos e os atos. Apesar desse trabalho clássico de Jodelet, situado no que se denomina abordagem processual ou sociogenética da TRS, ter avançado no estudo das relações entre representações sociais e práticas, foi no âmbito da abordagem estrutural, desenvolvida pelo chamado "Grupo do Midi", que houve maior amplitude de pesquisas, experimentais e de campo, visando aprofundar o tema em seus aspectos teórico e metodológico.

Algumas conceituações ou definições, têm contribuído para estudos de representação social, independente da abordagem adotada pelo pesquisador. Um ponto comum nesses trabalhos, que incita debates, é o questionamento: são as práticas sociais que determinam as representações, as representações que determinam as práticas, ou as duas são indissociáveis e interdependentes? (Rouquette, 2000; Flament, 2001; Campos, 2003; Abric, 2004; Wolter \& Sá, 2013). Pesquisas mostram que, dependendo do contexto social e das interações grupais, tanto as representações podem orientar práticas ou comportamentos, quanto as práticas podem provocar mudança da representação. Porém, como afirma Rouquette (2000), reforçado por Wolter e Sá (2013), não se trata de influência recíproca entre práticas e representações porque não há equivalência entre essas duas influências. Não se tratando de reciprocidade, para Rouquette (2000, p. 43) "convém tomar 
as representações como uma condição das práticas e as práticas como um agente de transformação das representações".

Abric (1994) propõe alguns fatores que estabelecem as relações entre representações e práticas: a) fatores culturais ligados à história e à memória coletiva do grupo, visto que as representações se inscrevem em um processo temporal e histórico; b) fatores ligados ao sistema de normas e de valores que constituem as representações: pode haver escolha que leva a condutas diferentes; c) fatores ligados à atividade do sujeito: existem processos de construção ou de reapropriação da realidade, fazendo com que a representação seja uma ação sobre essa realidade. Como afirma Campos (2003), duas das quatro funções atribuídas por Abric (2000) às representações sociais estão ligadas às condutas e aos comportamentos, ou seja, às práticas. São elas as funções "de orientação" e a "justificadora".

Para Rouquette (2000, p. 44), a prática abrange ao menos dois aspectos: "a realização de uma ação (conduta efetiva) e a frequência (ou, correlativamente, a familiaridade para o sujeito) dessa realização". A ação, segundo autor, tem duas vertentes: as maneiras de fazer e as consequências percebidas desse fazer. Ao se referir à influência das práticas sobre as representações, o mesmo autor propõe que ela envolve ao menos quatro aspectos: "prática como passagem ao ato"; "prática como recorrência"; "prática como maneira de fazer"; "prática como cálculo". Wolter e Sá (2013) valorizam essa contribuição de Rouquette para estudos sobre relações entre representações e práticas, afirmando que abordar os quatro aspectos pode auxiliar no enfrentamento da questão da polissemia da noção de "prática".

Com intenção de definir o que são "práticas sociais", Campos (2003, p. 29) se refere à concepção de Abric (1994) como "sistemas completos de ação" e à de Moliner (2001), como "conjuntos de condutas finalizadas pelos e para os grupos". De acordo com o autor,

a noção de prática teria como referência básica a ação, o agir dos grupos; e a ação comporta então, necessariamente, dois componentes, o vivido e o cognitivo. E é isso que nos permite uma certa legitimidade em estudar a ação, também por meio de instrumentos de natureza cognitiva" (Campos, 2003, p. 29).

Com fundamento nas considerações expostas sobre relações entre representações sociais e práticas, esse artigo tem intenção de apresentar reflexões derivadas da pesquisa de Santos (2016), que teve como objetivo investigar representações sociais de Unidade de Polícia Pacificadora (UPP) por professores do Ensino Fundamental no município do Rio de Janeiro e seus efeitos nas práticas da escola. A tese que se buscou defender foi a de que a UPP provocou melhoras nas práticas exercidas por professores nas escolas.

As Unidades de Polícia Pacificadoras (UPP) foram criadas pelo Governo do Estado do Rio de Janeiro em 2008, como política de Segurança Pública do Governo do Estado do Rio, em período que antecedeu eventos internacionais sediados no Rio de Janeiro: a Copa do Mundo em 2014 e os Jogos Olímpicos em 2016. A previsão seria criar mais de 40 UPPs até o ano de 2014 (no ano de 2016 existiam 38). Um dos objetivos apresentados oficialmente foi a pacificação de favelas ocupadas por faç̧ões criminosas, com retomada de territórios dominados por traficantes, enfraquecendo assim seu poderio bélico e o negócio das drogas. Um de seus fundamentos é o princípio da polícia de proximidade, tendo estratégia fundamentada na parceria entre a população e as forças policiais (Governo do Rio de Janeiro, 2013). 
Por definição, o policiamento de proximidade refere-se ao conceito de community policing, termo utilizado inicialmente nos Estados Unidos em finais dos anos de 1970 e início dos anos de 1980, para tentar resolver problemas relacionados ao sistema de justiça e a questões de natureza racial. De acordo com Ferreira (2014), o policiamento de proximidade traz em sua concepção a implementação de parcerias locais entre a polícia e os cidadãos. Propõe que policiais conheçam a área em que trabalham e façam abordagens orientadas para os problemas apresentados no contexto. Assim podem estabelecer relação de confiança com os moradores enquanto vão conhecendo diariamente as condições locais de sua área de atuação.

As UPPs foram inspiradas no sistema de policiamento comunitário utilizado nas cidades de Boston (Estados Unidos da América) - cidade pioneira -, Medellin e Bogotá (Colômbia), que obtiveram resultados positivos em relação à diminuição da violência (SILVA, 2010). Na cidade de Medellin, na Colômbia, a pacificação da favela de Santo Domingo, reduto do extraficante Pablo Escobar, contribuiu para a diminuição do número de homicídios na cidade, de 380 homicídios / 100 mil habitantes nos anos de 1990, para 34 / 100 mil em 2007. Ainda de acordo com Silva (2010), além de retomar o território, as UPPs também devem propiciar a chegada de serviços básicos de infraestrutura que possam fazer parte do cotidiano das pessoas. Livre do julgo dos traficantes, a população poderia assim ser favorecida com a entrada de investimentos públicos e privados, oferecendo oportunidades para as pessoas que residem nesses locais. Misse (2011), porém, lembra que inicialmente a maioria das UPP localizou-se em áreas mais nobres, como a zona sul da cidade. $O$ autor questiona se a UPPs tem o objetivo de proteger os moradores das favelas ou os do asfalto, e afirma que ela não conseguiu acabar com o tráfico de drogas.

A ampliação gradativa de UPP no Rio, e sua respectiva atuação na cidade, podem ter provocado um processo de familiarização das pessoas em relação a essa política de segurança pública, suscitando a produção de significados sobre esse objeto que começou a adentrar no universo cotidiano de alguns grupos. Um dos contextos afetados foi o das escolas, particularmente as relações sociais que envolvem os professores no chamado "processo de pacificação", na cidade do Rio de Janeiro, com essa nova política. Uma primeira questão a ser colocada é: que significados esses professores atribuem à UPP? Em seguida, para esses sujeitos: a) a UPP teria causado efeitos no entorno escolar?; b) suas práticas pedagógicas teriam sido afetadas?; c) a circunvizinhança da escola sofreu alterações com a presença da UPP? Ou seja, o conjunto de significados elaborados sobre esse novo objeto pode estar relacionado às práticas desenvolvidas na escola.

Para responder a essas questões foi adotada a Teoria das Representações Sociais (TRS), que permite investigar como está se dando a inserção desse objeto, "UPP", no universo simbólico e significante dos sujeitos (professores), considerando-se o contexto psicossocial em que estão situados. Como afirma Moscovici (2012, p. 46), "a representação social é a preparação para a ação, não só porque guia os comportamentos, mas, sobretudo porque remodela e reconstitui os elementos do ambiente no qual o comportamento deve acontecer".

Com fundamentação na TRS é possível investigar como se formam, na mente das pessoas, opiniões, crenças, valores, em relação a sujeitos e objetos, construídos nas interações grupais e sempre relacionados às práticas sociais. Esse referencial teóricometodológico permite verificar como um objeto surge socialmente e é apropriado por 
diferentes grupos. Campos (2003, p.22) faz referência às representações sociais como "uma construção sociocognitiva, quer dizer, uma construção submetida a uma dupla lógica cognitiva e social, submetida à influência do contexto discursivo e do contexto social". Tais representações fundamentam estudos psicossociais que investigam o saber do senso comum construído por grupos diversos, em uma perspectiva dinâmica.

$\mathrm{Na}$ abordagem moscoviciana da TRS (Moscovici, 1976/2012), cotidianamente as pessoas se defrontam com uma gama de informações oriundas de conhecimentos produzidos em diversos setores da sociedade (político, econômico, social, científico e tecnológico), que podem ser confrontados com sistemas internos de conhecimentos adquiridos por elas e seus grupos ao longo do tempo. Trata-se de um processo de familiarização com algo frequentemente novo, compreendido com base em saberes e experiências vividas. Esse processo de interpretação ou reinterpretação acontece nas relações sociais diárias travadas no trabalho, em casa, nas escolas, nos grupos de amigos e, atualmente, nas redes sociais. Como afirma Moscovici (1976/2012), nessas trocas as pessoas são solicitadas a se posicionarem em relação a um determinado assunto, o que o autor denomina como "pressão à inferência", que juntamente com a "dispersão da informação" e a "focalização", constituem as dimensões da realidade social associada à formação da representação social. A "dispersão da informação" se relaciona à quantidade de informações disseminadas sobre o objeto e que se tornam acessíveis ao sujeito. E a "focalização" se dá quando o indivíduo ou grupo privilegia alguns aspectos do objeto e mantém distância de outros, como se houvesse um "filtro" orientando a relação do sujeito com o objeto.

Para Moscovici (2010), as representações sociais têm duas funções principais: a) a de convencionalizar os objetos, pessoas ou acontecimentos, de tal sorte que determinam modelos, categorias e tipos partilhados pelas pessoas; e b) a de prescrever os comportamentos por meio de uma tradição que decreta o que deve ser pensado. Abric (2000) amplia esse entendimento, atribuindo quatro funções às representações: a) função de saber, que permite explicar e compreender a realidade; b) função identitária, que define a identidade e permite a proteção da especificidade dos grupos; c) função de orientação, que guia os comportamentos e as práticas; e d) a função justificadora, que permite a justificativa das tomadas de posição e dos comportamentos.

De acordo com Jodelet (2014), as representações sociais expressam uma forma pela qual os sujeitos apreendem os fatos e os acontecimentos da vida cotidiana, os dados do ambiente e as informações que nele circulam. Constituem-se em um conhecimento socialmente elaborado e partilhado, que se forma na base das experiências dos sujeitos e nas informações, nos saberes e nos modelos de pensamento recebidos e transmitidos pela tradição, pela educação e pela comunicação social. São assim, como afirmam Rateau, Moliner, Guimelli e Abric (2012), sistemas de opiniões, conhecimentos e crenças particulares a uma cultura, a uma categoria social ou a um grupo, em relação com objetos pertencentes ao seu ambiente social.

No presente estudo foram considerados professores de três escolas públicas (sujeitos da pesquisa) que supostamente estavam elaborando representações das Unidades de Polícia Pacificadora (objeto representado). Para melhor abordar tais representações, optou-se por privilegiar dois aspectos que podem evidenciar os efeitos da UPP nas práticas da escola: as práticas pedagógicas do professor e o entorno escolar. É possível que os três grupos de professores, por suas escolas estarem situadas em contextos geográficos e sociais diversos, apresentem representações diferentes em relação às UPP, devido ao tipo de relação que 
estabelecem com esse objeto (influência no cotidiano, informações a respeito e presença nas comunicações). O contexto de tais práticas, apresentado no item seguinte, deriva das características das escolas, situadas em locais distintos e supondo processos diferentes de familiarização com o objeto representado: uma escola situada ao lado de favela com UPP (Escola 1); uma ao lado de favelas sem UPP (Escola 2); e outra sem UPP e sem favelas nas proximidades (Escola 3).

\section{Método}

Foi adotada a perspectiva qualitativa em pesquisa, que de acordo com Fraser e Gondim (2004) parte do princípio de que a ação do homem tem um significado que não pode ser concebido apenas do ponto de vista quantitativo. Há destaque para a dimensão subjetiva, ou seja, para o que se constrói na mente do indivíduo e os significados que ele atribui a objetos, eventos e pessoas de seu contexto sociocultural.

Considerando a "grande Teoria das Representações Sociais" (Sá, 1998), o estudo aqui apresentado se aproxima mais do que é conhecido como abordagem "processual" (Sá, 1998), "culturalista" (Santos, 2005), ou "sociogenética" (Rateau et. al. 2012; Kalampalikis \& Apostolidis, 2016). A ênfase está mais na gênese de uma representação social levando em conta as dimensões histórica e cultural na compreensão dos processos simbólicos produzidos pelos grupos em contextos políticos, econômicos e socioeconômicos específicos. Trata-se de uma abordagem derivada dos estudos originais de Moscovici (1978/2012) e de Jodelet (1989/2015), que tem como fundamento os dois processos formadores das representações sociais, a "objetivação" e a "ancoragem", os quais tentam elucidar o modo como os grupos se familiarizam com objetos de seu entorno, atribuindo significado a eles e reconhecendo-os em suas redes de significações cognitivas e simbólicas.

Segundo Moscovici (2012, p. 100), a “objetivação" liga um conceito-ideia a uma imagem, permitindo "tornar real um esquema conceitual e substituir uma imagem por sua contrapartida material", ou seja, transforma conceito em imagem. A "ancoragem" procura dar sentido às imagens criadas por meio de conceitos pré-existentes. Por meio dela, os sujeitos transformam os objetos sociais em dispositivos relacionados a suas práticas sociais, comparando-os com formas já conhecidas. De acordo com Moscovici (2010, p. 61), a ancoragem "é um processo que transforma algo estranho e perturbador, que nos intriga, em nosso sistema particular de categorias e o compara com um paradigma de uma categoria que nós pensamos ser apropriada".

Com essa fundamentação foram investigadas representações sociais de UPP elaboradas por 30 professores dos anos finais do Ensino Fundamental de três escolas públicas do Rio, sendo 10 docentes em cada escola. Importante salientar que o material foi coletado no segundo semestre de 2015. Instabilidades na política de segurança pública no Rio de Janeiro poderiam afetar os dados, se colhidos em momentos posteriores.

A Escola 1 tem quase 100 anos de existência, atualmente com cerca de 900 alunos matriculados nos segmentos de Ensinos Fundamental (anos iniciais e finais) e Médio. Está situada em bairro da região central da cidade do Rio de Janeiro e é cercada por favelas com Unidades de Polícia Pacificadora. Em frente ao seu portão principal encontra-se instalada uma base da UPP (container), o que permite aos entrevistados a convivência diária com esse objeto social, cuja proximidade oferece maior possibilidade de afetar suas práticas escolares em relação à Escola 2 e à Escola 3. 
A Escola 2 tem cerca de 60 anos de existência, também com aproximadamente 900 alunos, do Ensino Fundamental (primeiro e segundo segmento) e Ensino Médio Profissionalizante. Está situada em um bairro da Zona Norte do Rio de Janeiro, a cerca de 700 metros de uma favela e a pouco mais de dois quilômetros da maior favela do bairro da Ilha do Governador, ambas sem UPP. Em contexto desfavorecido socioeconomicamente e apesar de ser um território dominado pelo tráfico, a região da escola pode ser considerada tranquila, sem grande movimento de pessoas, às margens de uma autopista. Devido à ausência de UPP, esse objeto social tende a afetar pouco as práticas cotidianas dos docentes.

A Escola 3, com mais de 100 anos de existência, oferece Ensino Fundamental (segundo segmento) e Ensino Médio, com cerca de 2500 alunos. Está situada em um bairro tradicional da Zona Norte do Rio, sem favelas em sua circunvizinhança, portanto, sem contato direto com a UPP, cuja setorização não atingiu essa região, com menos incidência de violência em relação a outras áreas da cidade. Nesse caso, como na Escola 2, os professores também não convivem com o objeto social UPP em seu cotidiano, favorecendo distanciamento de suas práticas escolares.

Embora tenham sido feitas observações nas três escolas, anotadas em diário de campo, o material apresentado aqui se constitui basicamente de entrevistas semidirigidas individuais e de um grupo focal na Escola 1 (nas outras duas escolas não foi possível formar grupos focais).

As entrevistas semidirigidas foram orientadas por um roteiro básico, composto por questões atinentes ao objeto de pesquisa e, por ser flexível, possibilitou aos sujeitos se expressarem mais livremente sobre assuntos surgidos espontaneamente no decorrer da conversa (Fraser e Gondim, 2004). Duas questões foram fundamentais na análise, por facilitarem a expressão de representações sociais sobre o tema: a) Se a UPP fosse uma coisa, um animal, um vegetal, um mineral, por exemplo, o que seria? Por que?; b) Se você fosse governador (a) do Estado do Rio de Janeiro o que faria em relação às UPP?

$\mathrm{Na}$ primeira foi aplicada a "indução de metáforas" como meio de investigar representações sociais, técnica que já vem sendo utilizada por pesquisadores da área como Mazzotti (1998) e Andrade (2006, 2007). Este procedimento tem por finalidade fazer com que o respondente desloque o discurso formal da entrevista para o campo informal e coloquial de sua fala. Para Lakoff e Johnson (2002, p. 45), "a metáfora é um recurso da imaginação, um adorno para o discurso, e que está inserida não só na linguagem cotidiana das pessoas como também na ação e nos pensamentos". Ela permite que, por meio da linguagem cotidiana, conceitos sejam compartilhados nos grupos. Por meio da segunda questão, foi possível verificar o que fariam os professores em relação à UPP, se colocados na posição de governadores do Rio de Janeiro, favorecendo assim a expressão de seus posicionamentos e intenções de ação quanto a essa política de segurança pública.

O grupo focal, para Gatti (2005), é uma técnica que decorre de trabalhos com grupos, muito utilizado nas pesquisas em Psicologia Social, cuja escolha dos participantes é realizada segundo critérios estabelecidos de acordo o problema estudado. Buscou-se assim reunir professores da Escola 1, onde existe uma instalação física da UPP em frente ao portão principal. Conforme a autora, os participantes devem ter alguma vivência com o tema em discussão. Neste caso, foram escolhidos professores com mais de cinco anos de trabalho nessa escola e que presenciaram momentos sem e com a UPP em suas práticas cotidianas. 
O material discursivo foi analisado com base na análise de conteúdo temática, segundo em Bardin (1994, p. 42). Para esta autora, a análise é composta de "técnicas de comunicação para obtenção de indicadores que conduzam a inferências sobre o conhecimento produzido pelas mensagens transmitidas pelos sujeitos". Com a decomposição das mensagens obtidas é possível identificar conceitos, categorias, frequências e ausências de termos que auxiliarão na interpretação dos textos.

Para Oliveira (2008, p. 570), o objetivo principal da análise de conteúdo é dar um tratamento às mensagens de forma que surjam evidências ou indicadores que possibilitem inferências de outra realidade. Com essa técnica é possível adentrar em vários conteúdos, explícitos ou não, presentes em qualquer escrito. De acordo com a autora, pode-se também "analisar as representações sociais de um determinado objeto; verificar o inconsciente coletivo em um tema específico; analisar a comunicação do dia a dia; e analisar o repertório de determinado grupo social".

A análise dos dados das entrevistas e do grupo focal foi assim realizada: a) organização dos dados digitados por meio de categorizações; b) estudo dos dados com estabelecimento de relações entre as categorias, a fim de permitir a construção de um esquema explicativo para o objeto de representação em cada grupo de professores; c) contraste entre os resultados dos três grupos.

\section{Resultados}

Para as três escolas foram construídas tabelas compostas por unidades temáticas, categorias e subcategorias, derivadas de três temas-chave: "violência"; "UPP - aspectos gerais"; "UPP - escola". Trechos das falas dos entrevistados foram inseridos em categorias e subcategorias, com as respectivas frequências. Para complementar a análise, foram construídos quadros específicos para as respostas às questões "Se a UPP fosse uma coisa, um animal, um vegetal, um mineral, por exemplo, o que seria? Por que? " e "Se você fosse governador (a) do Estado do Rio de Janeiro o que faria em relação às UPP?". Devido à extensão, essa análise não será exposta em sua totalidade. Optou-se por apresentar os "modelos figurativos", eventualmente "esquemas representacionais", da representação de UPP pelos três grupos de professores e seus efeitos nas práticas da escola. Eles resultam do conjunto da análise mencionada acima.

Moscovici (2012, p. 60) propõe uma estrutura para as representações sociais, em que duas faces são indissociáveis: a figurativa (imagem do objeto) e a simbólica (significado atribuído ao objeto pelo sujeito/grupo). Segundo o autor, "a representação transmite a qualquer figura um sentido e a qualquer sentido, uma figura". Os processos que entram em cena visam recortar a figura e dar-lhe significado, colocando o objeto no universo dos indivíduos, tornando-os naturais e interpretáveis, ou seja, "dividir um sentido por uma figura - objetivar - e uma figura por um sentido - ancorar os materiais que entram na composição de determinada representação".

Para materializar este processo de construção pelo qual as representações sociais se formam, Moscovici (2012, p. 114) propõe um "esquema" em que os elementos da representação se organizam, denominado "modelo figurativo", posteriormente "núcleo figurativo". Este modelo possibilita que os sujeitos possam apreender configurações abstratas tornando o objeto acessível aos componentes do grupo. De acordo com o autor, "quando o modelo é descrito como figurativo, é não só uma maneira de classificar as 
informações, mas o resultado da coordenação que caracteriza cada termo da representação".

Quando sujeitos de um determinado grupo se apropriam de informações e/ou conhecimentos sobre um dado objeto, há seleção de aspectos que são armazenados e outros que são descartados ao longo da familiarização com o objeto em função de fatores culturais, costumes, tradições e normas de cada grupo. Com base nessa "focalização", é possível a construção de um esquema que formará a figura que traduz uma imagem que dá coerência aos elementos que compõem o objeto da representação, permitindo aos sujeitos entende-lo e percebe-lo nas interações grupais. Como afirma Moscovici (2012, p. 115), "ao penetrar no meio social como expressão do real, o modelo figurativo se torna então natural, utilizado como se fosse copiado diretamente dessa realidade" (Moscovici, 2012, p. 115).

Com base nesses fundamentos, os resultados da análise serão expostos a seguir, por grupos de professores de cada escola, tendo como eixo as representações de UPP para os docentes e seus efeitos nas práticas da escola.

\title{
Escola 1
}

Ao longo da análise das entrevistas e do grupo focal foram observados elementos que parecem constituir o modelo figurativo da representação social de UPP para os professores da Escola 1, apresentado na Figura 1, como uma hipótese interpretativa.

Apesar de se referirem a situações de violência no Rio de Janeiro, que refletem insegurança pública na cidade, esse grupo não se sente ameaçado pela violência dentro da escola, como expressa a fala de um docente: "Atualmente não sinto nenhuma ameaça". Para a maioria desses professores, mesmo desconfiados quanto à continuação dessa política de segurança pública, a UPP trouxe melhoras em seu contexto social: "Foi uma mudança da água para o vinho a implantação da UPP [...] Antes da UPP, mais de uma vez, tiroteio foram duas vezes, costumava ser na sexta-feira". Porém criticam a falta de integração entre as políticas públicas no Rio e a dificuldade na formação de policiais:

\begin{abstract}
O que eu vejo que é necessário e imprescindível é a necessidade da participação de outros Órgãos do Estado, a polícia sozinha, a UPP, não vai resolver o problema da violência nessas comunidades. É fundamental que haja a participação da Secretaria de Obras, de Habitação, de Infraestrutura, Assistência Social, enfim, Educação, Saúde;

Hoje em dia eu olho as UPP assim, com pena dos PMs que estão ali expostos. Eles são preparados durante pouco tempo e é cobrado deles uma pontaria, uma boa ação, que eles sejam bons psicólogos, seja bom em tudo. Acho que faltou uma ação do Estado.
\end{abstract}

Quando se referem à escola, a maioria afirmou que a instalação da UPP provocou melhora em relação aos tempos em que não havia uma unidade na frente da instituição escolar. Alguns se expressam sobre mudanças em suas práticas no universo escolar:

Ah, eu me sinto mais segura;

No ir e vir, sim. Quer dizer, de alguma forma sim, porque se você está numa região que tem tiroteio toda semana, você está lá dando sua aula, é difícil você se manter absolutamente calma e todo mundo calmo sabendo que você está ali escutando tiro;

Localizada em frente, ela traz uma segurança imensa para os profissionais da instituição $e$ principalmente para as crianças, que estudam nela e que tem que circular na rua. É o que eu vejo, e o que eu vejo é positivo, é uma experiência positiva; 
O que mudou é que antigamente a polícia dava aquelas incertas, que hoje não dá porque tem UPP aqui. E nessas incertas muitas vezes causava um caos aqui na escola, porque as crianças entravam em desespero, eles já estavam condicionados a: "a polícia chegou, tem problema";

Foi uma mudança na qualidade de vida da escola e minha, impressionante. A UPP foi pra mim, assim, qualidade de vida. Eu já estava a ponto de desenvolver uma síndrome do pânico;

Eu acho que as coisas estão mais calmas, a escola demora a esvaziar. A escola esvaziava muito rápido, 12:10h era um deserto, sair daqui 14:20h era muito assustador. Era tenso;

Eu acho que ela altera num sentido talvez mais de abstrato, de paz, de você ter tranquilidade de realizar o seu trabalho.

A unidade da UPP próxima ao grupo de professores da Escola 1 favoreceu a formação de uma representação social desse objeto social presente em suas interações e práticas cotidianas. A objetivação em "segurança" pode ser explicada da seguinte maneira: o grupo se sente mais seguro com uma base da UPP em frente à escola, que possibilita o "direito de ir e vir" de quem frequenta a instituição escolar, Ihes trazendo "proteção" na escola e "esperança" em relação ao enfrentamento da violência na região e no Rio de Janeiro. Porém, ainda é necessário maior preparo da polícia de proximidade para garantir a estabilidade da UPP:

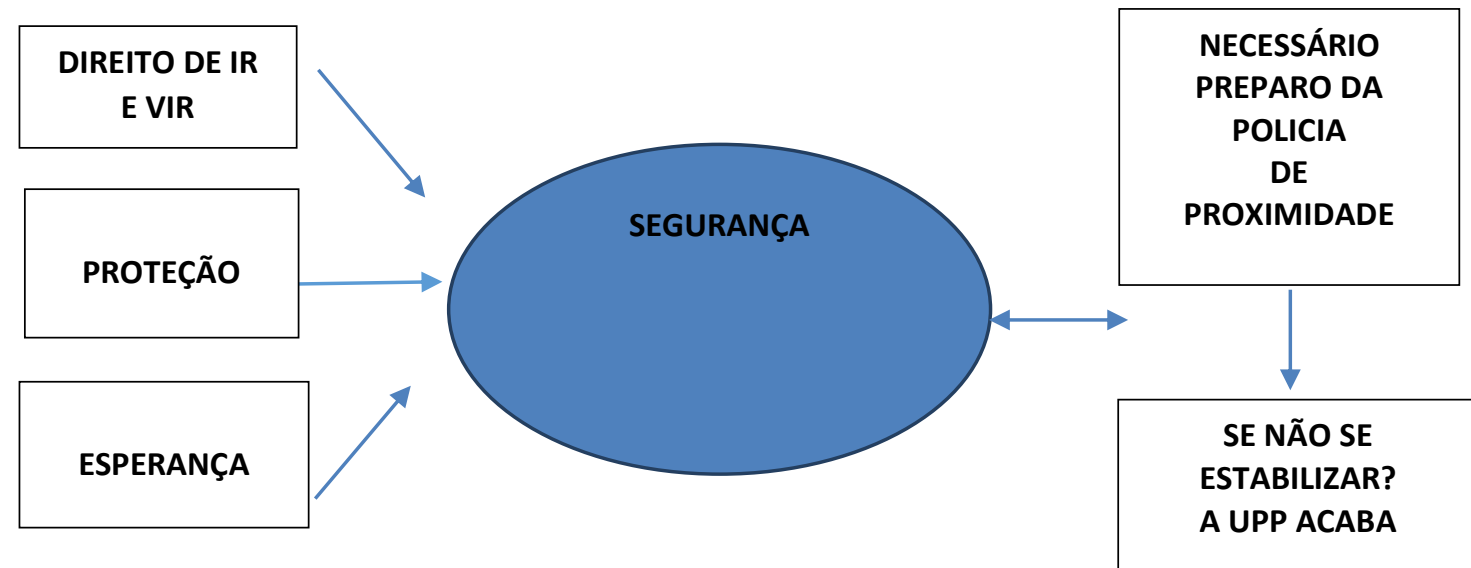

Figura 1 - Modelo figurativo da representação social de UPP por professores da Escola 1 - uma hipótese interpretativa

Um recurso que contribuiu para reforçar investigação da representação foi a "indução de metáforas". No conjunto das analogias, a expressão "cão de guarda" foi a que organizou o discurso e condensou o significado de UPP nos discursos dos professores da Escola 1. Essa "objetivação" mostra que o sentimento de "segurança", associado a "cão de guarda", teve efeitos favoráveis no cotidiano do grupo, consequentemente em suas práticas na escola. No entanto, a sobrevivência desse "cão de guarda" ainda não está garantida, devido ao despreparo de policiais e à falta de outras políticas sociais. Nesse sentido, se não houver estabilidade da política, "o cão morre" e a "UPP acaba".

\section{Escola 2}

Seguindo o mesmo modelo de análise adotado para a Escola 1, também se buscou um "modelo figurativo" da representação social de UPP para os professores da Escola 2. Porém, para esse grupo os elementos estavam mais dispersos, mostrando certo afastamento dos sujeitos em relação ao objeto estudado, em escola próxima a favela sem unidades de UPP. No 
conjunto, o grupo não indicou diferenças significativas em seu cotidiano com a implantação das UPP no Rio de Janeiro. Foi então proposto um "esquema representacional" na Figura 2, com elementos que expressam mais opiniões e representações amplas ligadas à UPP, e não exatamente uma representação social desse objeto.

Em relação à violência no Rio, fazem referências genéricas e não se sentem ameaçados dentro da escola: " "Não, dentro da escola não"; "Nem do ponto físico nem moral. Apesar de conviver com a área que tem sido pauperizada em termos de serviço público, violência bem próximo". Ou:

A gente está vulnerável o tempo todo né? Assaltos todo dia e eu me sinto muito insegura, não uso mais cordão, relógio valioso, até aliança eu tenho medo de usar por conta da violência. Eu já fui assaltada duas vezes.

Linha vermelha mesmo já peguei arrastão aqui na Linha vermelha saindo da llha do Governador, moro em Maricá, indo pela rodovia 106, nós já pegamos tudo parado ali, comunidade desceu para pista, pela BR 104 e os traficantes dando tiros e todo mundo no meio, toda população civil estava nos carros passando, muitos transeuntes, a população das comunidades jogando pedras nos carros, ou seja, a gente não sabia se saía do carro, ou se ficava dentro do carro, porque não tinha pra onde correr.

Apesar do sentimento de insegurança, de modo geral, na cidade do Rio de Janeiro, quando se referem à UPP, a maioria do grupo mostra desconfiança e expressa visão desfavorável, com muitas críticas à polícia e ao Estado, que não está cumprindo as promessas eleitoreiras:

Eu acho que é uma farsa, a UPP é uma farsa, é um marketing político do atual governo que não resolve nada, não acabou com o tráfico de drogas, e agora a violência está voltando né? O que a UPP fez foi intimidar o tráfico e impedir a circulação de marginais armados, mas não vejo isso como uma boa ocupação da comunidade. Acho que tem muito mais marketing político do que ações efetivas ali;

Acho que era uma tentativa deles que desde o princípio que não daria certo;

É necessário outro tipo de ocupação, é necessário você mudar a escola, é necessário que o Estado entre de outra forma, que o Estado venha trazer uma justiça aplicativa, venha dar uma educação decente, uma saúde decente, venha fazer uma promoção de eventos que possa ajudar a comunidade, de modo que o Estado não apareça ali como opressor através da polícia;

Em primeiro momento eu achei que fosse mudar muita coisa, mas pelo que a gente ouve falar, até uma vez a gente teve uma palestra aqui embaixo com o pessoal da Polícia Federal ou Polícia Civil, agora não lembro, foi um dos dois, em que ele estava falando sobre a violência e tal, e uma menina que mora aqui na Maré falou pra gente que continua tudo a mesma coisa, eles fazem uma maquiagem, e lá dentro continua tudo a mesma coisa;

O problema está nas pessoas que estão ali dentro, porque volta e meia você vê comandante da UPP caindo, volta e meia você vê soldados envolvidos com uma série de coisas;

A maior crítica dos moradores à UPP é o tratamento que está sendo dado aos moradores.

A maior parte do grupo não percebeu alterações nas práticas da escola com a implantação das UPP no Rio, e também não vislumbra mudanças caso houvesse uma unidade próxima, tendo em vista, além da desconfiança, o fato que a região guarda certa tranquilidade. Apesar da proximidade de favelas, a maioria dos professores expressou que não haveria alteração no entorno da escola em virtude de sua localização geográfica - região isolada do Bairro da Ilha do Governador -, próxima às Organizações Militares da Força Aérea Brasileira:

Dentro das escolas não vai mudar muita coisa não. Isso no sentido de trazer mais segurança pro trabalho, acredito que não. Não vejo dessa forma não; 
Eu já pensei realmente nisso, se é melhor com UPP ou não. Porque é uma área tranquila, apesar do território ser dominado principalmente, temos uma favela que é uma das maiores do Rio de Janeiro, que é o Dendê, que é dominada há anos, inclusive tem até a música que os alunos costumam cantar, conhecida, Tropa de Elite, que é ruim de invadir, o Dendê é ruim de invadir, que ficou conhecido por ser uma área dominada que ninguém mexe, e até hoje;

Não. Acho que não. Talvez se viesse mais pra cá, no Barbante, porque quando a UPP vai chegar, primeiro vem a polícia, eles tem que dominar a região, pode ser que aumente os transtornos na Ilha. Poucos alunos aqui são da comunidade do Dendê. A maioria é do Barbante;

Acho que não. Talvez porque eu não tenha essa vivência, eu não sei muito bem como funciona, mas eu acredito que não influenciaria tanto não.

Como expressa a última fala, a UPP não faz parta das práticas desse grupo na Escola 2. Trata-se, portanto, de um objeto que não está presente no cotidiano de trabalho dos professores. Observa-se que eles se referem mais ao Estado do que à UPP, o que explica a dificuldade de formarem uma representação social desse objeto. O que coordena seus discursos é a crítica ao Estado. Por essa razão, o "esquema representacional", apresentado na Figura 2, tem no centro o "Estado" ou o "Governo Estadual".

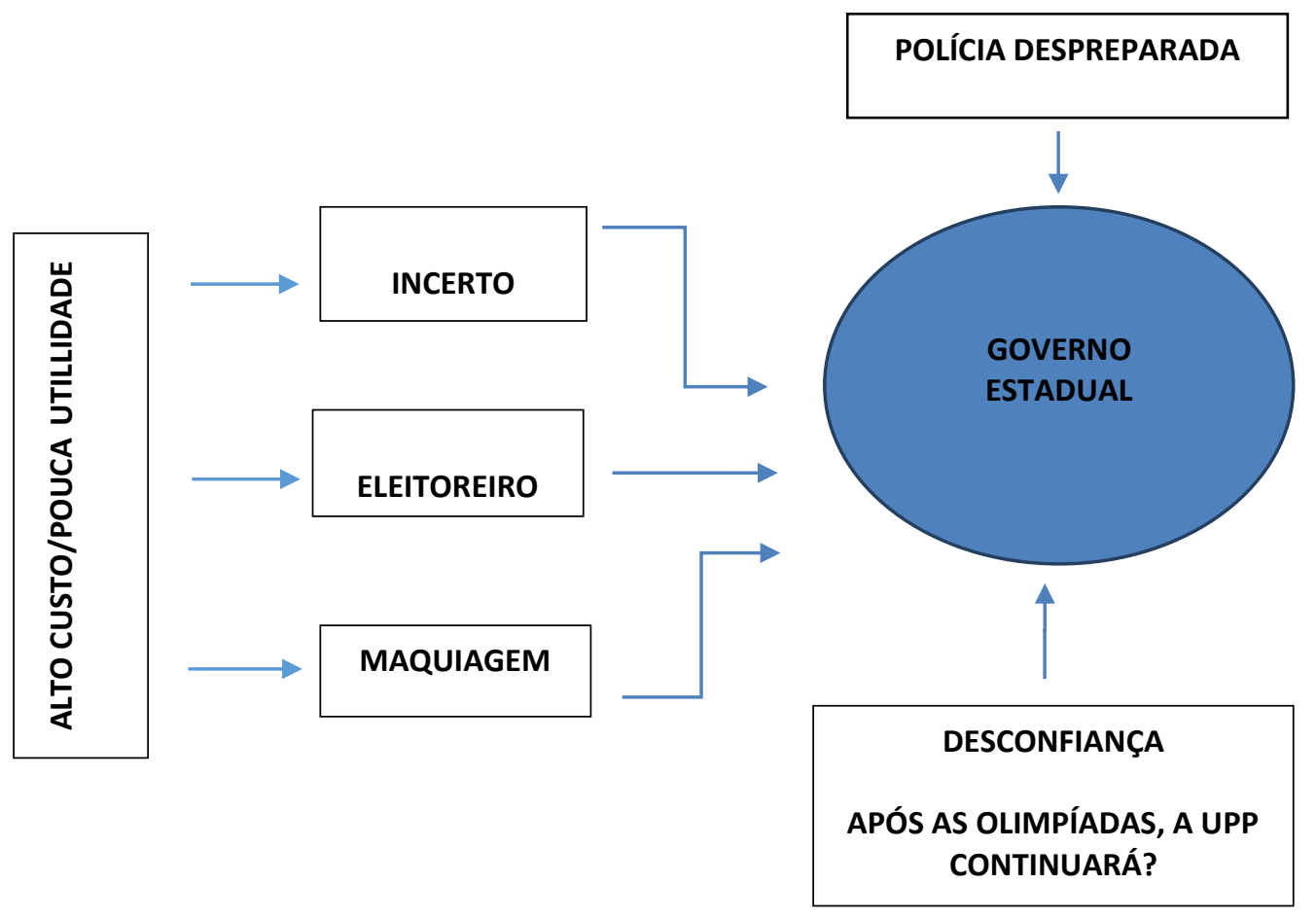

Figura 2 - Esquema representacional da UPP para os professores da Escola 2

A ideia apresentada no esquema pode ser assim explicitada: a política de segurança pública da UPP teve alto custo e resultou em pouca utilidade, pois é incerta, com o objetivo eleitoreiro de maquiar a situação de conflitos nas favelas cariocas. Com polícia despreparada e desconfiança, tanto no modo de implementação quanto na continuidade após grandes eventos no Rio de Janeiro, o Estado é o maior criticado por esse grupo. Complementando a análise com a "indução de metáforas", o termo "elefante branco", analogia feita alguns professores, organiza e condensa o significado do discurso do grupo, remetendo mais a uma característica do Estado, visto que a UPP não está presente diretamente na prática desses professores na escola. 


\section{Escola 3}

Para os dados obtidos no grupo de professores da Escola 3, situada em bairro sem favela e sem UPP, também se buscou a organização de um "modelo figurativo" da representação social de UPP. E como ocorreu com a Escola 2, foi possível somente propor um "esquema representacional" (ilustrado na Figura 3) porque o objeto UPP também pareceu estar distante das práticas cotidianas dos sujeitos, o que fez com que expressassem opiniões genéricas ou representações mais amplas, e não uma representação social enquanto sistema sociocognitivo.

Ao abordarem a questão da violência, a maioria destacou a situação do Rio de Janeiro, de modo geral, em situações em que o assunto é comentado nas interações do dia a dia, ou na mídia, como se essas situações não fossem enfrentadas na escola:

Já fui assaltado. Um professor nosso aqui, inclusive estava contando essa semana que foi rendido na porta de casa, mora no Meier, metralhadora na cara, então o Rio é perigoso, né?;

Eu estou aqui há quatro meses, moro num bairro tranquilo. E procuro fazer uma rotina a menos arriscada possível, então não tenho me sentido muito ameaçada não, só quando ligo a televisão $e$ vejo jornal, aí sim;

Bom o fato de o crime organizado ter se estabelecido principalmente nos últimos governos a partir do Brizola veio fortalecer o tráfico de tal forma que hoje é muito complicado você pensar em entrar em um morro, mesmos os pacificados, a violência é muito alta e a corrupção é muito grande;

Eu tive há pouco tempo, a questão de um mês ou dois atrás, fizeram um assalto bem cinematográfico ali na Linha Vermelha, na altura do Elevado do Caju, né? Vieram de moto um grupo de bandidos, e de repente fecharam o trânsito com as motos e saíram saqueando os carros, e aí os motoqueiros que vinham atrás, vinham anunciando que estava acontecendo um assalto. Foi aquele desespero do pessoal largando o carro para lá e saindo fora para fugir do assalto.

Em relação à UPP, a maioria mencionou favoravelmente essa política de segurança pública, parecendo acreditar em seu êxito, embora com ressalvas e enfatizando necessárias melhorias, com destaque para a formação dos policiais:

Eu vejo muito positivamente, embora saiba que algo implantado, vindo de fora da comunidade para dentro da comunidade, não foi uma escolha dos moradores. Não houve nenhuma é.... nenhum tratamento anterior, nenhuma conversa com a comunidade, então ela chega entrando com toda força e parece que essa força é militar, quando ela não traz o governo para dentro das comunidades, traz a polícia;

Eu acho que a UPP ajuda na comunidade onde ela está inserida, mas ela não tem grande efeito na cidade como um todo, onde, distante dela, ela não funciona, ela funciona onde ela está, ali, acho que talvez ela até agrave a situação por conta das pessoas né, saírem de onde a UPP está, $e$ procurarem outros locais onde não há UPP para que eles possam cometer seus delitos;

A UPP pode dar certo, mas ela ainda carece de muitos recursos, não é simplesmente um policiamento, há de se fazer um trabalho social forte, e isso não pode ser apenas pela secretaria de segurança, outras secretarias teriam que aderir a esse movimento;

A polícia militar carece de efetivo, carece de equipamento, e carece de estimulo financeiro, onde eles são maus remunerados, os equipamentos em algumas coisas são sofríveis;

Olha, ela amenizou, mas ainda não chegou ao ponto talvez que devesse chegar. Eu não entendo bem de segurança pública, mas a gente vê a UPP, mas mesmo assim a gente tem medo, né?

Quanto à relação da UPP com a escola, as questões foram colocadas no modo condicional, em razão da não existência de favela e de UPP na área da Escola 3. A maioria afirmou que a instalação de uma UPP, na área da escola, não provocaria qualquer diferença, 
em virtude do histórico de pouca incidência de atos de violência urbana no local. Em relação às práticas na escola, para a maioria dos professores a instalação de uma UPP não provocaria mudanças:

Não, não. Acho que aqui não há necessidade;

Eu acho que a UPP, ela é muito setorizada, mas está dentro de uma comunidade e não interfere nesse comportamento social nosso aqui;

Nossos alunos não são oriundos das comunidades próximas, eu acredito que não alteraria;

Aqui não porque o que acontece, aqui no colégio não tem morro, não tem comunidade aqui do lado;

Não, eu acho que não, nesse caso aqui acho que não, também não sei se eles implantariam, como não tem nenhuma área assim em foco, mas eu acredito que aqui não influiria;

o relacionamento aqui é bom, eu acho que o comércio, as pessoas que por aqui residem, elas têm uma boa visão do colégio, dos meninos daqui, né? Se vê que é do [...], já sabe que tem certa postura, certa educação.

Os professores da Escola 3 também se referem à UPP como uma política de segurança pública que não lhes afeta diretamente em seu cotidiano de trabalho na escola. Eles fazem menção a aspectos genéricos que ocorrem em suas comunicações ou que são veiculados na mídia. Nesse sentido, parecem ter opiniões sobre a UPP mais como uma política de segurança pública ainda ideal, que não se concretizou. Os elementos do "esquema representacional", expressos na Figura 3, se organizam em torno da ideia de uma "segurança ideal".

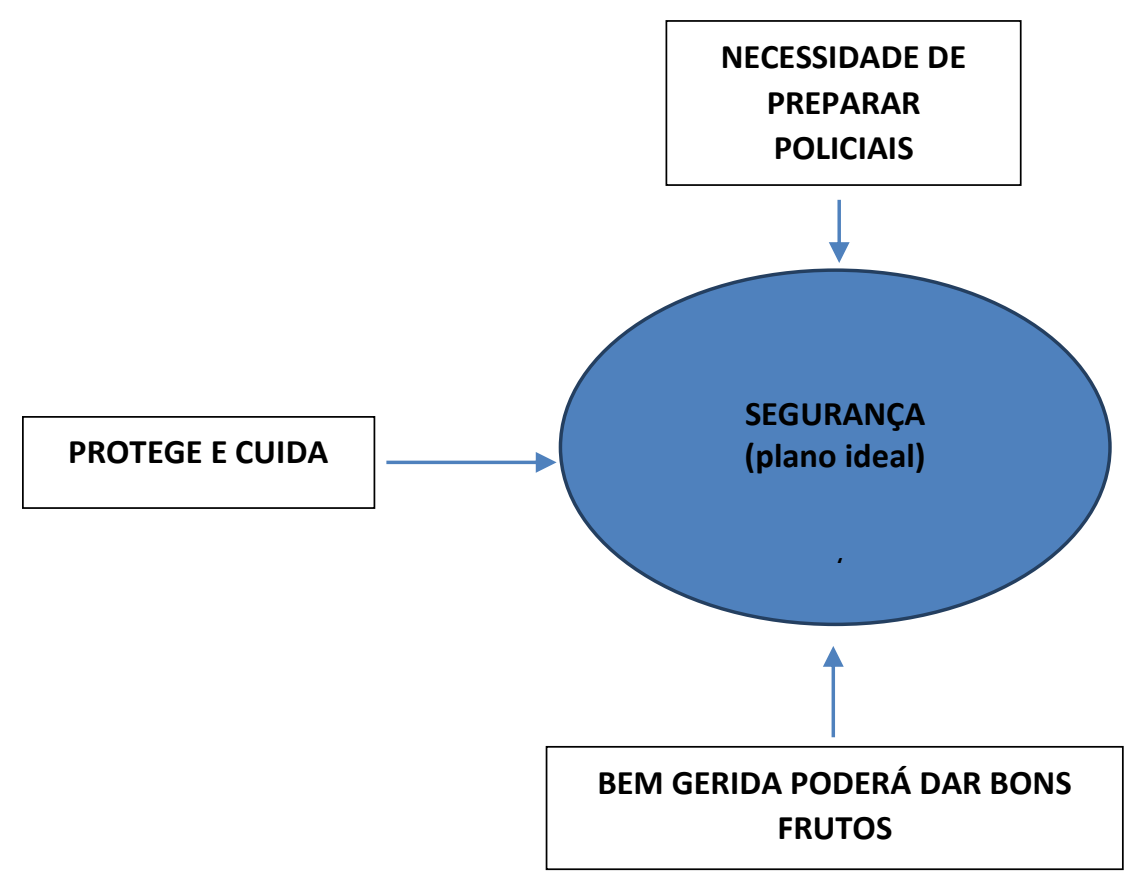

Figura 3 - Esquema representacional da UPP para os professores da Escola 3

O esquema acima mostra que, no plano ideal deveria haver uma UPP que oferecesse segurança às pessoas, protegendo e cuidando, com policiais bem preparados. Com a complementação da "indução de metáforas", nesse grupo se destacou a analogia com uma "árvore em crescimento" que, se bem gerida poderá criar raízes e dar bons frutos. Ou seja, percebe-se expectativa de uma política de segurança pública que precisa ser desenvolvida. 
Nesse grupo o objeto "UPP" também não está presente nas práticas cotidianas dos professores. As comunicações que estabelecem sobre o tema são mais gerais sobre o Rio de Janeiro e não afetam suas práticas na escola. Portanto, também não se pode dizer que há uma representação social formada.

\section{Discussão}

Apesar da síntese dos resultados possibilitar vários eixos de discussão, será privilegiada a reflexão sobre relações entre representações sociais e práticas com base na pesquisa mencionada. Considerando a tese de que a UPP provocou melhoras nas práticas exercidas pelos professores nas escolas, ela foi confirmada somente entre os professores da Escola 1, que conta com uma unidade da UPP em frente da instituição escolar. A figura 4 explicita elementos mencionados pelos entrevistados da Escola 1, referindo-se a efeitos que a UPP provocou em suas práticas escolares.

\begin{tabular}{|c|c|}
\hline ANTES DA UPP & DEPOIS DA UPP \\
\hline $\begin{array}{l}\text { Havia tiroteio que interferia nas atividades da } \\
\text { escola }\end{array}$ & Não há mais tiroteio \\
\hline $\begin{array}{l}\text { Tiroteio no entorno retinha docentes e alunos na } \\
\text { escola }\end{array}$ & Não há mais tiroteio \\
\hline Falta de segurança para chegar ao trabalho & Melhorou segurança para chegar ao trabalho \\
\hline $\begin{array}{l}\text { Alunos não tinham segurança para circular nos } \\
\text { arredores da escola }\end{array}$ & $\begin{array}{l}\text { Alunos tem mais segurança para circular nos arredores } \\
\text { da escola }\end{array}$ \\
\hline Bandidos armados circulavam no interior da escola & $\begin{array}{l}\text { Bandidos armados não circulam mais no interior da } \\
\text { escola }\end{array}$ \\
\hline $\begin{array}{l}\text { Presença de soldados do tráfico no universo da } \\
\text { escola }\end{array}$ & Não se vê mais soldados do tráfico no universo da escola \\
\hline Trabalho em sala de aula não era tranquilo & Trabalho em sala de aula é mais tranquilo \\
\hline $\begin{array}{c}\text { Havia ansiedade para sair da escola o mais cedo } \\
\text { possível }\end{array}$ & É possível ficar na escola até mais tarde \\
\hline $\begin{array}{l}\text { Necessário evitar realização de projetos na escola } \\
\text { aos sábados }\end{array}$ & É possível propor projetos na escola aos sábados \\
\hline $\begin{array}{c}\text { Falta de segurança para frequentar comércio na } \\
\text { região }\end{array}$ & Maior segurança para frequentar comércio na região \\
\hline $\begin{array}{l}\text { Desconhecidos parados em esquinas próximas à } \\
\text { escola provocavam medo }\end{array}$ & $\begin{array}{l}\text { Não há mais desconhecidos parados em esquinas } \\
\text { próximas à escola }\end{array}$ \\
\hline $\begin{array}{l}\text { Polícia aparecia de surpresa amedrontando alunos } \\
\text { e docentes }\end{array}$ & $\begin{array}{l}\text { Polícia não aparece mais de surpresa porque há unidade } \\
\text { da UPP na frente da escola }\end{array}$ \\
\hline $\begin{array}{l}\text { Presença irregular da polícia provocava } \\
\text { insegurança }\end{array}$ & $\begin{array}{l}\text { Policiais diariamente na frente da escola oferecem mais } \\
\text { segurança }\end{array}$ \\
\hline
\end{tabular}

Figura 4 - Mudanças provocadas pela UPP, segundo docentes da Escola 1

O Quadro acima expõe efeitos favoráveis da UPP nas práticas dos professores da Escola 1. Termos expressos por eles nas entrevistas, como "foi uma mudança da água para o vinho", ou "foi um divisor de águas", reforçam essa ideia, que remete à noção de "segurança". Outras analogias feitas por esses docentes, além de "cão de guarda", convergem para o mesmo significado, por exemplo:

Acho que eu coloquei um felino, mas acho que tinha que ser, na época eu acho que pensei que tinha que ser uma fêmea, pra gente ter a sensação de defesa. O que a gente espera dali? Que eles 
defendam a gente e principalmente, essa liberdade da gente de ir e vir, e a fêmea, acho que de qualquer espécie, ela tem essa coisa de proteger.

Segurança, como "proteção de mãe", aparece como característica atribuída à UPP por esse grupo de docentes, embora às vezes com desconfiança: "Comparei um pouco parecido com um leão, porque eu falei assim, que o leão defende, ele guarda, mas ele é violento, você confia desconfiando, tem alguma coisa a ver com isso". A visão mais favorável desse grupo à UPP difere sensivelmente dos outros dois grupos, os quais não tem esse objeto em suas práticas cotidianas. Para os docentes da Escola 2, a UPP fracassou como política de segurança pública, revelando o fracasso do próprio Estado. E no grupo da Escola 3, a UPP, também distante de suas práticas, poderia abstratamente se tornar uma política bem sucedida.

As diferenças nos resultados entre os três grupos mostram que o reflexo da presença da UPP nas práticas escolares, assim como das práticas na elaboração de representações sociais sobre esse objeto, depende do contexto de interação entre a UPP e os sujeitos. Se os campos de prática e de interações são diferentes, o campo representacional tende a ser diferente também.

Foram entrevistados três grupos de professores: 1) um que convive diariamente com a UPP, em contexto mais interativo, e que formou uma representação social de UPP com núcleo no termo "segurança", em analogia com "cão de guarda". Isso quer dizer que a UPP na frente da escola pode ter efeitos nas práticas, no sentido de se trabalhar com "maior segurança", ao mesmo tempo em que o trabalho com "mais segurança" pode contribuir para a formação de uma representação favorável da UPP, como política que trouxe "segurança". 2) um, situado em região socioeconômica desfavorecida, que não está em contato direto com o objeto, projetando no Estado a responsabilidade do problema. Nesse caso, não foi formada uma representação social de UPP, mas exposta uma crítica ao Governo Estadual em analogia com "elefante branco". Como esses sujeitos não tem práticas associadas à UPP, esse objeto social é associado ao "Estado"; 3) um situado em região socioeconômica favorecida, que também não convive a UPP em seu cotidiano. Como na Escola 2, não foram formadas representações sociais sobre o objeto, mas observadas opiniões e representações mais amplas que expressam "segurança" no plano ideal, em analogia com uma "árvore em crescimento". Ou seja, algo que pode dar frutos algum dia, embora distante das práticas desse grupo na escola.

O estudo mostrou uma situação social, no caso uma política de segurança pública implementada no Rio de Janeiro, percebida por grupos distintos. Tratando-se de um estudo de representação social, é importante lembrar o papel das práticas na construção de uma representação social de um novo objeto e também que, sem as práticas, os sujeitos não formam uma representação social, que supõe relações socioculturais específicas entre sujeito e objeto.

Outro aspecto a ser destacado é a relação do "modelo figurativo" (ou "núcleo figurativo"), que objetiva a representação do objeto social, com as práticas do grupo. Os comentários a seguir estão mais associados à Escola 1, onde foi possível perceber uma representação social. De acordo com Mazzotti (1998), o núcleo figurativo das representações sociais pode ser visto como resultado das metáforas provenientes dos discursos de cada grupo social. E como afirma Moscovici (2012, p. 26), a "representação social é organizada de 
imagens e linguagem, pois recorta e simboliza ações e situações que são ou se tornam comuns" ao grupo.

Abric (1994), ao comentar a obra de Jodelet $(1989,2015)$, menciona que as representações da doença mental na comunidade analisada se organizaram em um núcleo figurativo constituído de três elementos: "cérebro", "nervos", "mundo de carne e osso". Para o autor, esses elementos funcionam como esquemas, ou seja, são prescritores dos comportamentos e das práticas. Desse modo, as representações sociais são um guia para a ação, visto que permitem distinguir "doentes do cérebro" e "doentes dos nervos", engendrando assim condutas diferentes de acordo com a categoria ativada na representação.

Wolter e Sá (2013, p. 95-96) sintetizam o pensamento de Flament (1994) a esse respeito, no sentido em que a prática agiria

Como a interface entre as circunstâncias externas e os prescritores internos da representação. Como as prescrições orientam e determinam as práticas é natural que, caso um fator externo modifique algumas práticas, os prescritores se adequem à novidade; '[...] $\mathrm{O}$ aspecto prescritivo de uma cognição é o laço fundamental entre a cognição e a condutas que se supõe the corresponder.

Guimelli (2003) afirma, com base em estudos por ele realizados, que as representações sociais mudam a partir de um processo de ativação de esquemas ligados a um campo de representações. Isso parece acontecer quando as práticas correspondentes aos esquemas se tornam frequentes no grupo. $O$ autor se interessa por esse processo de ativação e pretende mostrar o modo como as práticas sociais estão diretamente relacionadas a ele. Assim os grupos se apropriam da realidade objetiva e a constroem progressivamente. Nessa mesma linha, de acordo com Campos (2003, p. 33): "Ideias sobre os objetos são ativadas de acordo com os contextos aos quais são submetidos os sujeitos".

Os resultados do estudo sobre representações de UPP para professores do Ensino Fundamental no Rio de Janeiro mostram diferenças em função do contexto em que estão inseridos, supondo também distinções entre as práticas de acordo com relações mais próximas ou distantes que estabelecem com o objeto. Assim, os elementos de ordem mais cognitiva que aparecem no "modelo figurativo" (objetivação) não podem ser dissociados das práticas dos sujeitos, enraizadas em seu contexto sociocultural (ancoragem).

Sendo a ancoragem o processo em que o grupo se familiariza com novos conhecimentos em função de categorias pré-existentes, visando ajustá-los à sua realidade, seria necessário buscar mais relações sociais e históricas em torno do objeto UPP nas práticas dos sujeitos. Uma pista poderia ser as expectativas de segurança dos moradores do Rio de Janeiro quando relacionadas às políticas de segurança pública do Estado, que se caracterizam pela descontinuidade. A proposta de Campos (2003) poderia contribuir quando reforça a importância do estudo das práticas sociais no contexto da ancoragem. 0 autor propõe duas dimensões de ancoragem: 1) a "sociológica", que deve ser encontrada nas estruturas sociais. São práticas desenvolvidas por grupos sociais e práticas institucionalizadas; 2) a "ideológica", que precisa abordar o enraizamento das representações sociais em grandes sistemas de crenças (macrorreguladores), como ideologias, religiões e valores sociais. Trata-se de um aspecto que precisa ainda ser aprofundado na pesquisa. 


\section{Conclusões}

O artigo procurou mostrar as contribuições de uma pesquisa a respeito de representações sociais de UPP para refletir sobre as relações entre representações sociais e práticas, assim como seus limites e perspectivas de novos estudos. Importante mencionar que tais reflexões sobre representações sociais e práticas foram despertadas na análise dos resultados e não postas previamente, como objetivo principal.

Os discursos dos três grupos de professores, e suas variações, mostraram que a apropriação de um objeto social acontece de acordo com experiências adquiridas ao longo do tempo. O mosaico dessas apropriações afeta a construção da identidade do grupo, orientando e justificando suas práticas. Observou-se que somente um dos grupos formou uma representação social, principalmente devido ao objeto UPP estar em suas práticas cotidianas, provavelmente suscitando mais discussões entre as pessoas por fazer parte de seu interesse imediato.

O estudo de Guimelli (2003) pode indicar pistas para aprofundar as relações entre representações e práticas aqui apresentadas. O autor investigou representações sociais sobre o "sujeito desviante" por três grupos: policiais comuns, policiais de elite e membros da Justiça (juízes, funcionários, educadores). Ele estudou os efeitos das práticas nos processos de ativação, com apoio do modelo que denomina "esquemas cognitivos de base" (Guimelli \& Rouquette, 1992). Assim verificou que as práticas "repressivas", "preventivas" ou "mistas" estão relacionadas às atividades cotidianas dos sujeitos. Desse modo, confirmou a hipótese de que cada elemento é ativado de maneira seletiva pelas situações geradas pelas práticas correspondentes, mostrando que as situações sociais favorecem a frequência de certas práticas, contribuem para a ativação de processos cognitivos específicos e determinam as representações.

Os estudos de Guimelli, de certa maneira, sugerem limites da pesquisa aqui apresentada, que se baseou em um contexto discursivo de entrevistas. Guimelli (2003) iniciou com entrevistas não dirigidas com o objetivo de inventariar os principais elementos que compõem o campo de representação dos grupos, para em seguida elaborar instrumentos mais específicos para estudar as práticas. Esse pode ser um caminho para aprofundar o "modelo figurativo" da representação social, supondo aproximações entre estudos feitos no âmbito da abordagem "processual" e da "estrutural". Vários debates podem ser provocados nesse sentido, com o desafio de pensar práticas sociais que implicam "assimilação de dados de natureza cognitiva e dados de natureza comportamental" (Campos, 2003, p. 28), sem perder de vista que todo estudo de representação social parte de um corpus praxeo-discursivo (Flament, 1987).

Para finalizar, destaca-se que a UPP, política de segurança pública proposta no Rio de Janeiro na atualidade, precisa ser contextualizada historicamente em um estudo de representação social. Como afirma Rouquette (2000, p. 45), "o estudo das representações sociais atuais pode, e deve contribuir a uma história do tempo presente". Abric (1994) também propõe que a análise de toda prática social, além de aspectos cognitivos, deve considerar as condições sociais, históricas e materiais nas quais está inscrita. Buscar a ancoragem que sustenta e explica o "modelo figurativo" da representação social pode contribuir nesse sentido. 


\section{Referências}

Abric, J-C. (1994). Pratiques sociales, représentations sociales. In: J.-C. Abric (Org.). Pratiques sociales et représentations (pp. 217-238). Paris: Presses Universitaires de France.

Abric, J-C. (2000). A abordagem estrutural das representações sociais. In: A. S. P. Moreira \& D. C. de Oliveira (Orgs.). Estudos interdisciplinares de representação social (2ª ed., pp. 27-38). Goiânia: AB.

Andrade, D. B. da S. F. (2006). O lugar feminino na escola: um estudo em representações sociais. Tese de doutorado. Pontifícia Universidade Católica de São Paulo, São Paulo, Brasil.

Andrade, D. B. da S. F. (2007). Se a escola pudesse ser outra coisa, que coisa ela seria? In: V Jornada Internacional e III Conferência Brasileira sobre Representações Sociais, Brasília.

Bardin, L. (1994). Análise de conteúdo. Lisboa: Edições Setenta.

Campos, P. H. F. (2003). A abordagem estrutural e o estudo das relações entre práticas e representações sociais. In: P.H.F. Campos \& M.C. da S. Loureiro (Orgs.). Representações sociais e práticas educativas (pp. 21-36). Goiânia: UCG.

Diário Oficial do Estado do Rio de Janeiro (2013). Decreto no 44.177 de 26 de abril de 2013, publicado no DOERJ em 29 de abril de 2013. Recuperado de https://www.jusbrasil.com.br/diarios/53701125/doerjpoder-executivo-29-04-2013-pg-1.

Ferreira, F. M. M. (2014). O Policiamento de Proximidade: O caso especial do programa "Comércio Seguro" da baixa da Cidade do Porto. Dissertação de mestrado. Universidade do Porto, Porto, Portugal.

Flament. C. (1987). Pratiques et représentations sociales. In : J.-L. Beauvois; R. V. Joule; J.-M. Monteil. Perspectives cognitives et conduites sociales. Tome 1: Théories implicites et conflits cognitifs (pp.143150). Cousset: Del Val.

Flament. C. (1994). Structure, dynamique et transformation des représentations sociales. In : J.-C. Abric.(Org.). Pratiques sociales et représentations (pp. 37-57). Paris: Presses Universitaires de France.

Flament. C. (2001). Pratiques sociales et dynamique des représentations. In: P. Moliner (Org.) La dynamique des représentations sociales - Pourquoi et comment les représentations se transforment-elles? (pp. 4358). Grenoble: Presses Universitaires de Grenoble.

Fraser, M. T. D. \& Gondin, S. M. G. (2004). Da fala do outro ao texto negociado: discussões sobre a entrevista na pesquisa qualitativa. Paidéia, Ribeirão Preto, 14(28), 139-152.

Gatti, B. A. (2005). Grupo focal na pesquisa em ciências sociais e humanas. Brasília: Liber Livro Editora.

Governo do Estado do Rio de Janeiro. (2013). O livro da UPP. Recuperado de http://www.upprj.com/upload/multimidia/LIVRO_UPPs.pdf.

Guimelli, C. (2003). La déviance vue par les instances chargées du maintien de l'ordre. In : J.-C. Abric (Org.) Exclusion sociale, insertion et prévention. (pp. 125-136). Toulouse: Érès.

Guimelli, C ; Rouquette, M.-L. (1992). Contribution du modèle associatif des schèmes cognitifs de base à I'analyse structurale de représentations sociales. Bulletin de Psychologie, 405, p. 196-202.

Jodelet, D. (1989). Folies et représentations sociales. Paris: Presses Universitaires de France.

Jodelet, D. (2014). Represéntation sociale: phénomènes, concept et théorie. In: S. Moscovici (Org.). Psychologie Sociale. (3a ed., pp. 363-384). “Quadrige”. Paris: Presses Universitaires de France.

Jodelet, D. (2015). Loucura e representações sociais (2a. ed.). Petrópolis: Vozes.

Jodelet, D.; Moscovici, S. (1990) Les représentations sociales dans le champ social. Revue Internationale de Psychologie Sociale, 3(3), 285-288.

Kalampalikis, N., \& Apostolidis, T. (2016). La perspective sociogénétique des représentations sociales. In : G. Lo Monaco, S. Delouvée \& P. Rateau. Les représentations sociales: Théories, méthodes et applications. (pp. 69-77). Louvain-la-Neuve: De Boeck Supérieur.

Lakoff, G. \& Johnson, M. (2002). Metáforas da vida cotidiana. Campinas: Mercado das Letras. 
Mazzotti, T. B. (1998). Investigando os núcleos figurativos como metáforas. I Jornada Internacional sobre Representações Sociais. CD-ROM. Natal-RN, p. 1-12.

Misse, M. (2011). Crime organizado e crime comum no Rio de Janeiro: diferenças e afinidades. Revista de Sociologia e Política, 19(40), 13-25.

Moliner, P. (Org.) (2001). La dynamique des représentations sociales - Pourquoi et comment les représentations se transforment-elles? Grenoble: Presses Universitaires de Grenoble.

Moscovici, S. (1976). La Psychanalyse, son image, son public. Paris: Presses Universitaires de France.

Moscovici, S. (2010). Representações sociais: investigações em Psicologia Social (7ạ. ed.). Petrópolis: Vozes.

Moscovici, S. (2012). A psicanálise, sua imagem e seu público. (Trad. Sonia Fuhrmann). Petrópolis: Vozes.

Oliveira, D. C. (2008). Análise de Conteúdo Temática Categorial: uma perspectiva de sistematização. Revista de Enfermagem da UERJ, 16(4), 569-576.

Rateau, P., Moliner, P., Guimelli, C. \& Abric, J- C. (2012). Social representation theory. In: P. A. M. Van Lange, K. A. W. Roglanksi \& E. T. Higgins (Orgs.). Handbook of theories of Social Psychology (pp. 477-497). Thousand Oaks, CA: Sage. Recuperado de http://www.europhd.eu/html/_onda02/07/PDF/30th_lab_scientificmaterial/rateau/rateau_moliner_gui melli_abric_2011_srt.pdf

Rouquette, M.-L. (2000). Representações e práticas sociais: alguns elementos teóricos. In: A.S.P. Moreira \& D. C. de Oliveira (Orgs.). Estudos interdisciplinares de representação social (2ª. ed., pp. 39-46). Goiânia: AB.

Sá, Celso P. (1998). Construção do objeto de pesquisa em representações sociais. Rio de Janeiro: Ed.UERJ.

Santos, M. F. S. (2005). A Teoria das Representações Sociais. In: M. F. S. Santos \& A. L. M Almeida (Orgs.). Diálogos com a Teoria das Representações Sociais (pp. 15-38). Recife: EdUFPE.

Santos, I. S. (2016). Representações sociais de Unidades de Polícia Pacificadora (UPP) por professores de escolas públicas no município do Rio de Janeiro e seus efeitos no entorno escolar. Tese de doutorado. Universidade Estácio de Sá, Rio de Janeiro, Brasil.

Silva, J. S. (2010). As Unidades de Policiais Pacificadoras e os novos desafios para as favelas cariocas. Disponível em:<http://observatoriodefavelas.org.br/wp-content/uploads/2013/06/Aspectos-humanos-das-favelascariocas.pdf>. Acesso em set. 2014.

Wolter, R. P. \& Sá, C. P. (2013). As relações entre representações e práticas: o caminho esquecido. Revista Internacional de Ciencias Sociales y Humanidades. XXXIII(1 e 2), 87-105. Recuperado de https://www.researchgate.net/publication/275889356_As_relacoes_entre_representacoes_e_praticas_ o_caminho_esquecido. 